Original article

\title{
Risk factors associated with asthma among adults in Khuzestan, southwest Iran
}

\author{
Esmaeil Idani $^{\mathrm{a}, \mathrm{b}}$, Hanieh Raji ${ }^{\mathrm{a}}$, Elham Maraghi ${ }^{\mathrm{c}}$, Hamidreza Aghababaeian ${ }^{\mathrm{d}}$, \\ Farzan Madadizadeh $^{\mathrm{e}}$, Dastoorpoor Maryam ${ }^{\mathrm{f}, *}$ \\ a Department of Internal Medicine, Air Pollution and Respiratory Diseases Research Center, Ahvaz Jundishapur University of Medical Sciences, Ahvaz, Iran \\ ${ }^{\mathrm{b}}$ Department of Internal Medicine, School of Medicine, Shahid Beheshti University of Medical Sciences, Tehran, Iran \\ ${ }^{\mathrm{c}}$ Department of Biostatistics and Epidemiology, Public Health Faculty, Ahvaz Jundishapur University of Medical Sciences, Ahvaz, Iran \\ ${ }^{\mathrm{d}}$ Nursing and Emergency Department, Dezful University of Medical Sciences, Dezful, Iran \\ ${ }^{\mathrm{e}}$ Research Center of Prevention and Epidemiology of Non-Communicable Disease, Department of Biostatistics and Epidemiology, School of Public Health, Shahid Sadoughi \\ University of Medical Sciences, Yazd, Iran \\ ${ }^{\mathrm{f}}$ Department of Biostatistics and Epidemiology, Air Pollution and Respiratory Diseases Research Center, Ahvaz Jundishapur University of Medical Sciences, Ahvaz, Iran
}

\section{A R T I C L E I N F O}

\section{Keywords:}

Asthma

Risk factors

Adult

\begin{abstract}
A B S T R A C T
Introduction: There is limited information on the risk factors of epidemiological of bronchial asthma in adults. This research aims at studying the risk factors associated with asthma in adults.

Methods: The validated European Community Respiratory Health Survey questionnaire was used to conduct a field study on adults aged 20-65 years old in Khuzestan province, Iran. For this, the researchers used a two-stage cluster sampling method. Univariate and multiple logistic regression modeling were used to obtain odds ratio of potential risk factors.

Results: The researchers handed out 5720 questionnaires of which 5708 were filled in. 231 cases of 478 individuals with asthma were male. The results showed that having airway hyper responsiveness $(\mathrm{OR}=13.52$; 95\% CI: 9.61-19.02), having a family history of asthma (OR $=2.88$; 95\% CI: $2.23-3.71)$, residence in urban areas $(\mathrm{OR}=2.15 ; 95 \% \mathrm{CI}: 1.43-3.21)$, the presence of mildew in the building (OR $=1.95 ; 95 \% \mathrm{CI}: 1.29-2.92)$ and the location of the house in the main street with respect to the auxiliary road $(\mathrm{OR}=1.44 ; 95 \% \mathrm{CI}$ : 1.14-1.82), respectively, were the most potent risk factors for asthma in adults. However, the presence of dense green space in the $200-\mathrm{m}$ radius of the residential home (OR $=1.69 ; 95 \% \mathrm{CI}: 1.30-2.20)$ and home gardening (OR $=1.42 ; 95 \%$ CI: 1.12-1.80) are the most important protection factors against asthma.

Conclusions: This study showed the association between some environmental factors with the odds of having asthma. These factors can be considered in primary prevention programs for asthma.
\end{abstract}

\section{Introduction}

Asthma is a common disease of the airway system occurring worldwide. ${ }^{1}$ Deaths caused by asthma have declined significantly over the past years. However, asthma is not curable, and existing asthma treatment regimens just control the disease. Thus, its burden is still rising. $^{2-4}$

Usually, risk factors cause an individual to develop asthma and respiratory problems. Nonetheless, asthma can occur without any risk factor. When a risk factor is inherent in a person, the likelihood that they will develop it is increased and vice versa(5). Relationships are reported between risk factors and asthma in childhood. Meanwhile, advancements in the pathogenesis of asthma have been significance.
Yet, various aspects of it remain to be clarified.

Many "protective" and "predisposing" factors in the pathogenesis of asthma are involved due to multifaceted interactions between exposure to environmental factors and genetic predispositions. Genetically, more than 100 genes have been identified, and many gene polymorphisms have been associated with the onset of asthma. However, none of them alone or in combination cannot predict the onset of the disease. Environmental factors, often playing a role in the onset of asthma in children, are as follows: smoking, allergens, air pollution and respiratory infections. ${ }^{6-10}$ The association between exposure to air pollution and the risk of asthma and respiratory diseases has been observed in several studies. ${ }^{11-16}$ Most of these risk factors are derived from epidemiological studies, the causality of which are hard to prove and

\footnotetext{
* Corresponding author.

E-mail address: dastoorpoor-m@ajums.ac.ir (M. Dastoorpoor).
} 
require interventional studies.

Few studies have dealt with risk factors associated with adult asthma. In this regard, in a study done by Kirenga et al. (2019), in Uganda among 3416 adolescents and adults, the results showed that 323 had asthma. Also, the results showed that smoking, family history for asthma, nasal allergy, biomass smoke exposure and urban residence were independently associated with asthma. ${ }^{17}$ In study by $\mathrm{Ng}$ et al. (2018), in Singapore among adults stated that having cats and dogs at home, having rugs and carpets and smoking have been risk factors related to asthma. ${ }^{18}$ Also in study by Obel et al. (2017), in Kinshasa, Congo on the 1088 adults over the age of 18 reported that the prevalence of asthma has been $6.9 \%$, and family atopy and the presence of cats at home were the most important risk factors for asthma. ${ }^{19}$

A more comprehensive understanding of asthma risk factors is needed. Such understanding could be helpful in developing health, preventing asthma, and the need for pharmaceutical treatments that help reduce the spread of asthma worldwide. Although the variety and the complicated history of asthma intrudes the endeavors to examine the role played by each risk factor or to study prevention strategies using a single intervention, avoiding risk factors for control asthma symptoms is essential. Patients cannot change their family history or their gender. However, they can avoid smoking, inhaling polluted air, allergens and prevent overweight that controls asthma. ${ }^{10,20,21}$ Through identifying risk factors, we can hopefully prevent or control asthma. Our objective in this study was to explore the risk factors that may be associated with adult asthma.

\section{Methods}

This is a cross-sectional research which was carried out from September 2017 to February 2018 during six months. The population of the study was adults in the Khuzestan Province. The study was conducted in 24 counties using samples from 27 cities and 17 villages. Our criteria for including samples in the research were being male or female of 20-65 years of age and willing to take part in the study. Individuals were excluded if they had a specific disease, disability, a mental problem, or dementia if prevented them from cooperating.

\subsection{Sample size}

The sample size was calculated as 2600 people. To determine the sample, the researchers relied on a study by Mehrabi et al., which projected asthma prevalence in adults aged 15-65 years in Kurdistan as $0.023{ }^{22}$ The error rate was considered as the coefficient of prevalence and this coefficient has been $25 \%(\mathrm{~d}=0.0054) .^{23}$ The National Census of 2016 was also used which indicates that the population of the Khuzestan Province is 4710509 people. The following formula calculates the optimum sample size for our study. Using the design effect $2,{ }^{24}$ we calculated the sample size as 5200 respondents. As we projected that normally $10 \%$ of the individuals might not cooperate, we estimated the sample size as 5720 .

$$
\begin{gathered}
n=\frac{N z_{1-\frac{\alpha}{2}}^{2} p(1-p)}{d^{2}(N-1)+z_{1-\frac{\alpha}{2}}^{2} p(1-p)}, N=4710509, \alpha=0.05, z_{1-\frac{\alpha}{2}}=1.96, p=0.023 \\
, d=0.0054 \Rightarrow n \simeq 2600
\end{gathered}
$$

\subsection{Sampling strategy}

This research used the two-stage cluster sampling method. First, the researchers selected the clusters in Khuzestan Province. Next, we selected 143 clusters from the clusters through random systematic sampling. In doing so, we considered the proportion of probability to size. The clusters in cities and villages were calculated according to the region's population's proportional to the whole population of the
Province. The data for census enumeration areas, geographic map and the population each cluster were collected through the latest census data and communication with the Iranian Statistics Center (2017). Finally, 143 clusters remained, each cluster included 40 persons. Each cluster consisted of 8 males and 8 female aging 20-29 years old, 8 males and 8 female aging 30-44 years old, and 4 male and 4 female aging 45-65 years.

After receiving the necessary trainings, enumerators began sampling. They were handed maps of selected clusters and referred to the address of each cluster from the southwest point of that cluster in the clockwise direction. For each cluster, sampling was carried out until 40 respondents agreed to participate.

\subsection{Questionnaire}

To examine the presence of asthma in the samples, we used the ECRHS questionnaire. ${ }^{25}$ The ECRHS was utilized in domestic, standardization and localization studies. ${ }^{26}$ Drawing on the questionnaire, the definition of current asthma is the recent use of anti-asthma medicines or experiencing an asthma attack during the last 12 months. ${ }^{25}$ The ECRHS questionnaire in Iran was validated by Tazesh et al.(2013). ${ }^{27}$ In this study, this validated questionnaire was used for data collection.

As regards the risk factors for asthma, after review of the literature, the following factors were identified and added to the questionnaire:

The current location, gender, age, birth season, birth weight, breastfeeding, education level, marital status, employment status, number of family members, smoking status, accommodation type (apartment, house), ownership status (landlord, tenant), residential area, age of the building (under 20 years of age, over 20 years of age), duration of residence, humid rooms, mold pollution in the building, beetles in the building, the heating system of the building (gas, electric), the presence of flower and plant in the house, the presence of a garden in the house, pets at home, having a pet in the bedroom, keeping taxidermies in bedroom, the type home-cleaning tool, the presence of rug in the bedroom, an open window over $30 \mathrm{~min}$ a day, the largest path within $100 \mathrm{~m}$ of home (main street, auxiliary road), existence of dense green space in a radius of $200 \mathrm{~m}$ to the residence, family history of asthma, allergic rhinitis, eczema and airway hyper responsiveness, reaction status to bee stings, history of exposure to dust and toxic substances.

The researchers received the written informed consent from the respondents after acquiring the needed licenses for carrying out the study and coordinating with the officials. The respondents were assured that their information would be kept confidential.

\subsection{Statistical methods}

Results were presented as absolute frequencies and percentages for qualitative variables. Normality assumption was assessed using the Shapiro-Wilk test. Quantitative variables were presented as median with interquartile ranges (IQR). First, univariate logistic regression models were used to examine whether there were relationships between the role of predictor variables and Asthma status. The odds ratio (OR) was calculated and presented with a $95 \%$ confidence interval (CI). Any variable having a $\mathrm{p}$-value less than 0.25 was selected as a candidate for the multiple logistic regression analysis. Backward stepwise logistic regression modeling was then used to obtain a subset of factors that were associated with asthma. We used likelihood ratio tests to judge whether or not to remove factors. Statistical analysis was performed using the statistical software R3.5.1. P values below 0.05 were assumed significant.

\section{Results}

Of 478 individuals with Asthma, 231 cases (48.97\%) were male. Family history of Asthma was revealed in 333 (70.9\%) of individuals 
Table 1

The important risk factors for Asthma (Univariate logistic regression).

\begin{tabular}{|c|c|c|c|c|c|}
\hline Characteristics & Without Asthma & With Asthma & Odds Ratio & $95 \% \mathrm{CI}$ & P-value \\
\hline Region & & & & & $<0.001 *$ \\
\hline Rural & 664 (12.8) & $31(6.5)$ & Ref & - & \\
\hline Urban & $4530(87.2)$ & 447 (93.5) & 2.11 & $(1.45-3.06)$ & \\
\hline Gender & & & & & 0.433 \\
\hline Male & 2615 (50.8) & $231(48.9)$ & Ref & - & \\
\hline Female & $2530(49.2)$ & $241(51.1)$ & 1.078 & $(0.89-1.30)$ & \\
\hline Age group & & & & & $<0.001 *$ \\
\hline $20-29$ & $2068(40.0)$ & $161(34.0)$ & Ref & - & \\
\hline $30-44$ & 2053 (39.7) & $182(38.4)$ & 1.13 & $(0.91-1.42)$ & \\
\hline $45-65$ & $1046(20.2)$ & $131(27.6)$ & 1.60 & $(1.26-2.05)$ & \\
\hline Birth Season & & & & & $0.015^{*}$ \\
\hline Spring & $700(18.7)$ & $77(24.0)$ & Ref & - & \\
\hline Summer & $971(25.9)$ & $79(24.6)$ & 0.74 & $(0.53-1.02)$ & \\
\hline Fall & $853(27.7)$ & $83(25.9)$ & 0.88 & $(0.63-1.22)$ & \\
\hline Winter & $1229(32.7)$ & $82(25.5)$ & 0.60 & $(0.43-0.83)$ & \\
\hline Birth weight & & & & & 0.140 \\
\hline Normal & 5025 (99.2) & $446(98.5)$ & Ref & - & \\
\hline Low Birth Weight & $43(0.8)$ & $7(1.5)$ & 1.83 & $(0.82-4.10)$ & \\
\hline Breast Feeding & & & & & $<0.001 *$ \\
\hline Yes & $5022(98.7)$ & 427 (95.5) & Ref & - & \\
\hline No & $68(1.3)$ & $20(4.5)$ & 3.45 & $(2.08-5.75)$ & \\
\hline Education $^{\text {a }}$ & & & & & $0.040 *$ \\
\hline Illiterate/Low & $1723(35.0)$ & $159(34.7)$ & Ref & - & \\
\hline Moderate & $1890(38.4)$ & $154(33.6)$ & 0.88 & $(0.70-1.11)$ & \\
\hline High & $1310(26.6)$ & $145(31.7)$ & 1.19 & $(0.94-1.51)$ & \\
\hline Marital Status & & & & & $0.011^{*}$ \\
\hline Single & $2048(39.4)$ & $160(33.5)$ & Ref & - & \\
\hline Married & $3146(60.6)$ & $318(66.5)$ & 1.29 & $(1.06-1.57)$ & \\
\hline Job & & & & & $0.031^{*}$ \\
\hline Have a job & $1346(53.8)$ & $128(46.9)$ & Ref & - & \\
\hline Jobless & $1157(46.2)$ & $145(53.1)$ & 1.31 & $(1.02-1.69)$ & \\
\hline Family Size & & & & & $<0.001 *$ \\
\hline$>3$ & $4124(84.5)$ & $338(76.5)$ & Ref & - & \\
\hline$\leq 3$ & $757(15.5)$ & $104(23.5)$ & 1.67 & $(1.32-2.11)$ & \\
\hline Family History of Asthma & & & & & $<0.001 *$ \\
\hline No & $3221(62.8$ & $137(29.1)$ & Ref & - & \\
\hline Yes & $1911(37.2)$ & $333(70.9)$ & 4.09 & $(3.33-5.03)$ & \\
\hline Active Smoking & & & & & $<0.001 *$ \\
\hline No & $4382(85.0)$ & $367(78.1)$ & Ref & - & \\
\hline Yes & $771(15.0)$ & $103(21.9)$ & 1.59 & $(1.26-2.01)$ & \\
\hline Accommodation Type & & & & & $<0.001 *$ \\
\hline House & 4675 (90.6) & $384(81.2)$ & Ref & - & \\
\hline Apartment & $487(9.4)$ & $89(18.8)$ & 2.22 & $(1.73-2.85)$ & \\
\hline Ownership Status & & & & & $<0.001 *$ \\
\hline Landlord & $4287(83.3)$ & $359(76.1)$ & Ref & - & \\
\hline Tenant & $860(16.7)$ & $113(23.9)$ & 1.56 & $(1.25-1.96)$ & \\
\hline \multirow[t]{2}{*}{ Residential Area } & median $\left(\mathrm{Q}_{1}-\mathrm{Q}_{3}\right)$ & median $\left(Q_{1}-Q_{3}\right)$ & & & $0.006^{*}$ \\
\hline & $110.0(95-160)$ & $100.0(90-150)$ & 0.99 & (0.995-0.999) & \\
\hline \multirow[t]{2}{*}{ Duration of Residency } & median (IQR) & median (IQR) & & & 0.178 \\
\hline & $10.0(4-20)$ & $10.0(4-18)$ & 0.99 & $(0.98-1.00)$ & \\
\hline Age of the Building & & & & & 0.634 \\
\hline Under 20 years of age & $1553(62.3)$ & $150(60.7)$ & Ref & - & \\
\hline Over 20 years of age & $941(37.7)$ & $97(39.3)$ & 1.06 & $(0.81-1.39)$ & \\
\hline Heating System & & & & & 0.891 \\
\hline Gas & $5088(98.4)$ & $466(98.3)$ & Ref & - & \\
\hline Electric & $83(1.6)$ & $8(1.7)$ & 1.05 & $(0.50-2.18)$ & \\
\hline Garden in House & & & & & $0.005^{*}$ \\
\hline Yes & $1773(34.3)$ & $132(27.9)$ & Ref & - & \\
\hline No & 3395 (65.7) & $341(72.1)$ & 1.34 & $(1.09-1.66)$ & \\
\hline Existence of Green Space & & & & & $<0.001^{*}$ \\
\hline Yes & $4054(80.1)$ & $324(70.3)$ & Ref & - & \\
\hline No & $1006(19.9)$ & $137(29.7)$ & 1.70 & $(1.37-2.10)$ & \\
\hline Largest Path within $100 \mathrm{~m}$ of home & & & & & $<0.001 *$ \\
\hline Auxiliary Road & $3527(68.4)$ & $249(52.9)$ & Ref & - & \\
\hline Main Street & $1631(31.6)$ & $222(47.1)$ & 1.92 & $(1.59-2.33)$ & \\
\hline Opening Window more than $30 \mathrm{~min}$ in day & & & & & $0.009^{*}$ \\
\hline Yes & 4220 (81.9) & $362(77.0)$ & Ref & - & \\
\hline No & $933(18.1)$ & $108(23.0)$ & 1.34 & $(1.07-1.69)$ & \\
\hline Humid Rooms & & & & & 0.433 \\
\hline No & $2636(50.8)$ & $233(48.9)$ & Ref & - & \\
\hline Yes & $2550(49.2)$ & $243(51.1)$ & 1.07 & $(0.89-1.30)$ & \\
\hline Mold in House & & & & & $<0.001 *$ \\
\hline No & $5000(96.5)$ & 431 (91.1) & Ref & - & \\
\hline Yes & $180(3.5)$ & $42(8.9)$ & 2.70 & $(1.90-3.84)$ & \\
\hline
\end{tabular}


Table 1 (continued)

\begin{tabular}{|c|c|c|c|c|c|}
\hline Characteristics & Without Asthma & With Asthma & Odds Ratio & $95 \% \mathrm{CI}$ & P-value \\
\hline Beetle in House & & & & & $0.044^{*}$ \\
\hline No & $2647(51.0)$ & $218(46.2)$ & Ref & - & \\
\hline Yes & $2539(49.0)$ & $254(53.8)$ & 1.21 & $(1.00-1.46)$ & \\
\hline Pet in House & & & & & 0.643 \\
\hline No & $4763(92.1)$ & $432(91.5)$ & Ref & - & \\
\hline Yes & $407(7.9)$ & $40(8.5)$ & 1.08 & $(0.77-1.52)$ & \\
\hline Pet in bed Room & & & & & $<0.001 *$ \\
\hline No & 5069 (99.1) & $446(97.2)$ & Ref & - & \\
\hline Yes & $45(0.9)$ & $13(2.8)$ & 3.28 & $(1.75-6.13)$ & \\
\hline Dry Pet in Room & & & & & $<0.001 *$ \\
\hline No & 5119 (99.4) & $453(97.6)$ & Ref & - & \\
\hline Yes & $33(0.6)$ & $11(2.4)$ & 3.76 & $(1.89-7.50)$ & \\
\hline Dry plant in bedroom & & & & & $<0.001 *$ \\
\hline No & $4972(96.0)$ & $433(90.6)$ & Ref & - & \\
\hline Yes & $207(4.0)$ & $45(9.4)$ & 2.49 & $(1.78-3.49)$ & \\
\hline Type Home Cleaning Tool & & & & & $0.001 *$ \\
\hline Electric & $5108(98.6)$ & $456(96.4)$ & Ref & - & \\
\hline Sweep & $75(1.4)$ & $17(3.6)$ & 2.53 & $(1.48-4.33)$ & \\
\hline Rug in Room & & & & & $0.007^{*}$ \\
\hline Yes & $5062(97.8)$ & $455(95.8)$ & Ref & - & \\
\hline No & $114(2.2)$ & $20(4.2)$ & 1.95 & $(1.20-3.16)$ & \\
\hline Allergic Rhinitis & & & & & $<0.001 *$ \\
\hline No & $3957(76.2)$ & $169(35.4)$ & Ref & - & \\
\hline Yes & $1235(23.8)$ & $308(64.6)$ & 5.839 & $(4.78-7.11)$ & \\
\hline Eczema & & & & & $<0.001 *$ \\
\hline No & 4706 (90.7) & $351(74.2)$ & Ref & - & \\
\hline Yes & $482(9.3)$ & $122(25.8)$ & 3.39 & $(2.70-4.25)$ & \\
\hline Airway Hyper Responsiveness & & & & & $<0.001 *$ \\
\hline No & $3436(66.2)$ & $46(9.6)$ & Ref & & \\
\hline Yes & $1758(33.8)$ & $432(90.4)$ & 18.35 & $(13.47-25.0)$ & \\
\hline Reaction to bee stings & & & & & $0.042^{*}$ \\
\hline Normal & 4703 (91.7) & $402(88.9)$ & Ref & - & \\
\hline Abnormal & $424(8.3)$ & $50(11.1)$ & 1.38 & $(1.01-1.88)$ & \\
\hline Exposure to Dust and Toxic Substances & & & & & 0.310 \\
\hline No & $934(18.1)$ & $77(16.2)$ & Ref & - & \\
\hline Yes & $4222(81.9)$ & $397(83.8)$ & 1.141 & $(0.885-1.47)$ & \\
\hline
\end{tabular}

Values presented as No. (\%), unless otherwise stated.

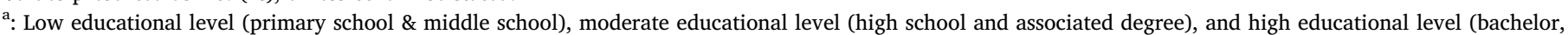
master and doctorate degree).

*P Values is significant.

with Asthma. Regarding symptoms of allergic, airway hyper responsiveness and allergic rhinitis were the most reported findings $(90.4 \%$ and $64.6 \%$, respectively).

Univariate logistic regression analyses indicated that individuals with airway hyper responsiveness were 18.35 times more likely to have Asthma (95\% CI: 13.47 to $25.0, \mathrm{p}<0.0001$ and Table 1 ). Also, individuals with allergic rhinitis were significantly more likely to have Asthma (Odds Ratio (OR): 5.83, 95\% CI: 4.78 to 7.11, p $<0.0001$ and Table 1). However, significant association was found between other factors and Asthma status (Table 1).

According to the results of multiple logistic regression analyses, residence in urban areas, having a family history of asthma, having airway hyper responsiveness, the location of the house in the main street with respect to the auxiliary road, the presence of mold in the building, the presence of dense green space in the 200-m radius of the residential home and home gardening were the only predictors of Asthma in the final model (Table 2).

\section{Discussion}

The results of this study showed that having airway hyper responsiveness and family history of asthma, residence in urban areas, the presence of mold in the building and the location of the house in the main street regarding to the auxiliary road, respectively, were the most potent risk factors for asthma in adults participating in the study. However, the presence of dense green space in the 200 -m radius of the residential home and home gardening are the most important
Table 2

The important risk factors for Asthma (Multiple logistic regression).

\begin{tabular}{llll}
\hline Characteristics & Odds Ratio & $95 \%$ CI & P-value \\
\hline Region & & & $<0.001^{*}$ \\
$\begin{array}{l}\text { Rural } \\
\text { Urban }\end{array}$ & Ref & - & \\
Family History of Asthma & 2.15 & $(1.43-3.21)$ & \\
No & & & $<0.001^{*}$ \\
Yes & Ref & - & \\
Garden in House & 2.88 & $(2.23-3.71)$ & \\
Yes & & & $0.003^{*}$ \\
No & Ref & - & \\
Existence of Green Space & 1.42 & $(1.12-1.80)$ & $<0.001^{*}$ \\
Yes & & & \\
No & Ref & - & \\
Largest Path within 100 m of home & 1.69 & $(1.30-2.20)$ & \\
Auxiliary Road & & & $0.002^{*}$ \\
Main Street & Ref & - & \\
Mold in House & 1.44 & $(1.14-1.82)$ & \\
No & & & 0.001 \\
Yes & Ref & - & \\
Airway Hyper Responsiveness & 1.95 & $(1.29-2.92)$ & \\
No & & & \\
Yes & Ref & - & \\
\hline
\end{tabular}

*P Values is significant.

protection factors against asthma.

The results showed that having airway hyper responsiveness increases the odds of having asthma by 13.5 times. Observations indicate 
that airway hyper responsiveness and asthma are not the same phenomenon. Airway hyper responsiveness is a necessary and inadequate condition for the development of asthma. Patients with airway hyper responsiveness are at risk for developing asthma. In this regard, according to a study done by Stern et al., in 2008 and Arshad et al., in 2005, among young adults and women who were recently diagnosed with asthma, it was shown that most of them were at the age of 6 years with wheezing and airway hyper responsiveness symptoms. ${ }^{28,29}$

Also, the results showed that having allergic rhinitis and eczema increases the odds of having asthma up to $5.8 \%$ and 3.4 times. Atopy refers to the genetic potential of creating allergic rhinitis, eczema (atopic dermatitis), asthma and allergic conjunctivitis. Atopy brings about acute allergic reactions to common allergens, especially airborne and nutrient substances. In other studies, it has also been proven that some children with eczema or atopic dermatitis experience asthma and may end up in severe asthma in adulthood. ,6,30 $^{\text {no }}$

In the study, having a family history of asthma increased the odds of having asthma by 2.9 times. Genetic predisposition is a known and recognized risk factor for asthma. A history of asthma in family escalates the risk of asthma in children. It is evident an inherited background does not necessarily mean a direct Mandelin pattern. Numerous locuses have been related to asthma in many chromosomes. However, for various reasons, diagnosing the disease at the genetic level has led to disappointing results. A more comprehensive understanding about environmental and genetic interactions would result in therapeutic opportunities. Consequently, it minimizes the risk of asthma and averts its progress. ${ }^{5,6,31,32}$

Along with other ${ }^{33,34}$ studies, this study showed that living in urban areas close to villages increases the odds of having asthma. The prevalence of asthma increases with urbanization due to different infrastructures, socio-economic factors and lifestyle. These factors include more environmental exposure, more air pollution in cities than villages, fewer green spaces in cities, lower lifestyles and possibly more stress. Several studies have shown that exposure to polluted air (including ozone contaminants) increases the risk of asthma. ${ }^{35,36}$ Understanding the importance and interaction between these factors is essential for planning interventional strategies. Evidence suggests that the difference in the prevalence of asthma among children from an ethnic group in a population is not primarily due to genetic differences, but because of the exposure to several environmental and lifestyle factors.

Mold contamination in a building increases the odds of having asthma. Numerous studies have also shown that children who are exposed to moisture and mold at home are more prone to developing asthma symptoms. However, exposure to endotoxins (cell wall parts of the gram-negative bacteria present in the house dust) is inversely related to the incidence of childhood asthma. ${ }^{37-40}$

The results of this study showed that dampness in living rooms increases the odds of having asthma by 1.07 times. This could be due to the presence of mold alternaria in the residence, which its relationship with the prevalence of asthma has been reported. ${ }^{41}$

In contrast, the results of the present study showed that ventilating a home naturally (opening the window more than half an hour a day), or with ventilating equipment such as air condition, reduces the amount of mold and fungus ${ }^{41,42}$ and thus is a protective factor against asthma.

As regards the location of a home in the main street toward an auxiliary road, which was introduced as a risk factor for adult asthma in this study, no report was found. Limited reports of exposure to traffic and asthma symptoms have been reported in children. ${ }^{4-45}$ Proximity to traffic with higher levels of air pollution (including highways, freeways and main streets) may reduce pulmonary growth, ${ }^{46}$ and also increase the risks of asthma and its symptoms during childhood.

The results of the adjusted model indicated that the presence of dense green space in a 200-m radius of a residential home and having a garden at home is a protective factor for the risk of asthma in adults. It seems that green space can be preventive in the development of asthma by helping to reduce air pollution in contaminated cities such as
Khuzestan province and should be considered by urban authorities. Studies in high income countries also showed that contact with anomalous animals on farms has a protective effect on children's asthma. As it seems that the presence of green space near the place of residence may have a protective effect on asthma. ${ }^{47}$

In this study, the presence of live and taxidermy pets in bedrooms was significantly associated with odds of having asthma. There are different and contradictory results in relation to contact with animals and the occurrence of asthma. The evidence found by the research indicates that there is a positive relationship between early contact with animals in low-income countries and the increased risk of asthma in childhood. ${ }^{48}$

Smoking in this study, like other studies, ${ }^{5,6,49}$ has been associated with increased odds of having asthma. Smoking may increase the symptoms of asthma, although cough and phlegm which are a sign of chronic bronchitis, is more common in smokers. However, asthma can begin at any age. Other studies have also shown that those individuals whose mothers are smokers during pregnancy or passive smokers are more prone to asthma. ${ }^{50}$

\section{Conclusion}

Asthma occurs due to complex interactions between immune response to allergens and environmental exposures. The incidence and prevalence of asthma has increased over the past two to three decades. However, the immunologic, genetic and environmental mechanisms that lead to the development of asthma are not well identified. Nonetheless, some risk factors have already been identified.

Asthma is common in Khuzestan and is related to risk factors of home, air pollution and other factors. Primary prevention strategies are needed to reduce exposure to known risk factors and control asthma. In this regard, reduced environmental risk factors including: Avoiding smoking, preventing indoor pollution (via indoor ventilation), occupational pollution and controlling air pollution is strongly encouraged, and primary prevention of asthma should be one of the main objectives of asthma management. Cohort studies are needed to better discover and understand the role of these factors in the development and exacerbation of asthma.

\section{Ethics approval and consent to participate}

Ethics License of the present study was acquired from the Ethics Committee of Ahvaz Jundishapur University of Medical Sciences (Code of ethics: IR.AJUMS.REC.1395.352).

\section{Funding}

This work was funded by Ahvaz Jundishapur University of Medical Sciences (Grant Number: APRD-9504).

\section{Conflicts of interest}

The authors declare that they have no competing interests.

\section{Acknowledgements}

The authors are grateful to all respondents in this study.

\section{References}

1. Idani E, Raji H, Madadizadeh F, Cheraghian B, Shoshtari MH, Dastoorpoor M Prevalence of asthma and other allergic conditions in adults in Khuzestan, southwest Iran, 2018. BMC Public Health. 2019;19(1):303.

2. Masoli M, Fabian D, Holt S, Beasley R. Global Initiative for Asthma (GINA): Global Burden of Asthma. 2004; 2004.

3. Eder W, Ege MJ, von Mutius E. The asthma epidemic. $N$ Engl $J$ Med. 2006;355(21):2226-2235. 
4. Bateman ED, Hurd S, Barnes P, et al. Global strategy for asthma management and prevention: GINA executive summary. Eur Respir J. 2008;31(1):143-178.

5. Beasley R, Semprini A, Mitchell EA. Risk factors for asthma: is prevention possible? The Lancet. 2015;386(9998):1075-1085.

6. Hekking P-PW, Bel EH. Developing and emerging clinical asthma phenotypes. $J$ Allergy Clin Immunol: In Pract. 2014;2(6):671-680.

7. Group ECRHS. Genes for asthma? An analysis of the European community respiratory health survey. Am J Respir Crit Care Med. 1997;156(6):1773-1780.

8. Abramson M, Kutin JJ, Raven J, Lanigan A, Czarny D, Walters EH. Risk factors for asthma among young adults in Melbourne, Australia. Respirology. 1996;1(4):291-297.

9. Sunyer J, Anto J, Kogevinas M, et al. Risk factors for asthma in young adults. Spanish group of the european community respiratory health survey. Eur Respir $J$. 1997;10(11):2490-2494.

10. Janson C, Anto J, Po Burney, et al. The European Community Respiratory Health Survey: what are the main results so far? Eur Respir J. 2001;18(3):598-611.

11. Goudarzi G, Geravandi S, Idani E, et al. An evaluation of hospital admission respiratory disease attributed to sulfur dioxide ambient concentration in Ahvaz from 2011 through 2013. Environ. Sci. Pollut. Res. 2016;23(21):22001-22007.

12. Geravandi S, Sicard P, Khaniabadi YO, et al. A comparative study of hospital admissions for respiratory diseases during normal and dusty days in Iran. Environ. Sci. Pollut. Res. 2017;24(22):18152-18159.

13. Dobaradaran S, Geravandi S, Goudarzi G, et al. Determination of cardiovascular and respiratory diseases caused by PM10 exposure in Bushehr, 2013. J Mazandaran Univ. Med. Sci. 2016;26(139):42-52.

14. Khaniabadi YO, Daryanoosh SM, Amrane A, et al. Impact of middle eastern dust storms on human health. Atmos. Pollut. Res. 2017;8(4):606-613.

15. Khaniabadi YO, Fanelli R, De Marco A, et al. Hospital admissions in Iran for cardiovascular and respiratory diseases attributed to the Middle Eastern Dust storms. Environ. Sci. Pollut. Res. 2017;24(20):16860-16868.

16. Daryanoosh M, Goudarzi G, Rashidi R, et al. Risk of morbidity attributed to ambient PM10 in the western cities of Iran. Toxin Rev. 2018;37(4):313-318.

17. Kirenga BJ, de Jong C, Katagira W, et al. Prevalence and factors associated with asthma among adolescents and adults in Uganda: a general population based survey. BMC Public Health. 2019;19(1):227.

18. Ng T, Hui K, Tan WC. Prevalence of asthma and risk factors among Chinese, Malay, and Indian adults in Singapore. Thorax. 1994;49(4):347-351.

19. Obel KB, Ntumba KJM, Kalambayi KP, Zalagile AP, Kinkodi KD, Munogolo KZ. Prevalence and determinants of asthma in adults in Kinshasa. PLoS One. 2017;12(5) e0176875.

20. Weinmayr G, Forastiere F, Büchele G, et al. Overweight/obesity and respiratory and allergic disease in children: international study of asthma and allergies in childhood (ISAAC) phase two. PLoS One. 2014;9(12) e113996.

21. Beuther DA, Sutherland ER. Overweight, obesity, and incident asthma: a meta-analysis of prospective epidemiologic studies. Am J Respir Crit Care Med. 2007;175(7):661-666.

22. Mehrabi S, Delavari A, Moradi G, Ghaderi E. Prevalence of asthma among 15 to 64 years old in kurdistan, Iran 2006. Iran J Epidemiol. 2009;4(3):93-98.

23. Pourhoseingholi MA, Vahedi M, Rahimzadeh M. Sample size calculation in medical studies. Gastroenterol. Hepatol. from Bed to Bench. 2013;6(1):14.

24. Bennett S, Woods T, Liyanage WM, Smith DL. A Simplified General Method for ClusterSample Surveys of Health in Developing Countries. 1991; 1991.

25. Burney U, Chinn S, Luczynska C, et al. Variations in the prevalence of respiratory symptoms, selfreported asthma attacks, and use of asthma medication in the European Community Respiratory Health Survey (ECRHS). Eur Respir J. 1996;9:687-695.

26. Rahimi-Rad M, Gaderi-Pakdel F, Salari-Lak S. Smoking and asthma in 20-44-year-old adults in Urmia, Islamic Republic of Iran. East Mediterr Health J. 2008;14(1):6-16.

27. Tazesh B, Shaabani A, Fazlollahi MR, et al. Prevalence of asthma symptoms and smoking behavior among 20-44 years old adults in Tehran: a telephone survey. Health. 2013;5(03):469.

28. Stern DA, Morgan WJ, Halonen M, Wright AL, Martinez FD. Wheezing and bronchial hyper-responsiveness in early childhood as predictors of newly diagnosed asthma in early adulthood: a longitudinal birth-cohort study. The Lancet. 2008;372(9643):1058-1064.

29. Arshad SH, Kurukulaaratchy RJ, Fenn M, Matthews S. Early life risk factors for current wheeze, asthma, and bronchial hyperresponsiveness at 10 years of age. Chest. 2005;127(2):502-508.

30. Kusel MM, de Klerk NH, Kebadze T, et al. Early-life respiratory viral infections, atopic sensitization, and risk of subsequent development of persistent asthma. J Allergy Clin Immunol. 2007;119(5):1105-1110.

31. Martinez FD, Vercelli D. Asthma. Lancet. 2013 Oct 19;382(9901):1360-1372 PubMed PMID: 24041942. Epub 2013/09/18. eng.

32. Guerra S, Martinez FD. Asthma genetics: from linear to multifactorial approaches. Annu Rev Med. 2008;59:327-341.

33. Robinson CL, Baumann LM, Romero K, et al. Effect of urbanisation on asthma, allergy and airways inflammation in a developing country setting. Thorax. 2011:158956 thx 2011.

34. Andrew Aligne C, Auinger P, Byrd RS, Weitzman M. Risk factors for pediatric asthma: contributions of poverty, race, and urban residence. Am J Respir Crit Care Med. 2000;162(3):873-877.

35. Carrillo G, Patron MJP, Johnson N, Zhong Y, Lucio R, Xu X. Asthma prevalence and school-related hazardous air pollutants in the US-Mexico border area. Environ Res. 2018;162:41-48.

36. Trasande L, Thurston GD. The role of air pollution in asthma and other pediatric morbidities. J Allergy Clin Immunol. 2005;115(4):689-699.

37. Tischer C, Chen C-M, Heinrich J. Association between domestic mould and mould components, and asthma and allergy in children: a systematic review. Eur Respir J. 2011 erj01840-2010.

38. Gehring U, Strikwold M, Schram-Bijkerk D, et al. Asthma and allergic symptoms in relation to house dust endotoxin: phase two of the international study on asthma and allergies in childhood (ISAAC II). Clin Exp Allergy. 2008;38(12):1911-1920.

39. Mendell MJ, Mirer AG, Cheung K, Tong M, Douwes J. Respiratory and allergic health effects of dampness, mold, and dampness-related agents: a review of the epidemiologic evidence. Environ Health Perspect. 2011;119(6):748-756.

40. Quansah R, Jaakkola MS, Hugg TT, Heikkinen SAM, Jaakkola JJ. Residential dampness and molds and the risk of developing asthma: a systematic review and meta-analysis. PLoS One. 2012;7(11) e47526.

41. Krieger J, Jacobs DE, Ashley PJ, et al. Housing interventions and control of asthmarelated indoor biologic agents: a review of the evidence. J Public Health Manag Pract: JPHMP. 2010;16(5 0):S11.

42. organization WH. Dampness and mould: WHO guide-lines for indoor air quality. Copenhagen, WHO Regional Office for Europe, http://www euro who int/data/ assets/pdf_file/0017/43325_E._2009;92645.

43. Bernstein DI. Traffic-related pollutants and wheezing in children. $J$ Asthma 2012;49(1):5-7.

44. Gasana J, Dillikar D, Mendy A, Forno E, Vieira ER. Motor vehicle air pollution and asthma in children: a meta-analysis. Environ Res. 2012;117:36-45.

45. Brunekreef B, Stewart AW, Anderson HR, et al. Self-reported truck traffic on the street of residence and symptoms of asthma and allergic disease: a global relationship in ISAAC phase 3. Environ Health Perspect. 2009;117(11):1791.

46. Gehring U, Gruzieva O, Agius RM, et al. Air pollution exposure and lung function in children: the ESCAPE project. Environ Health Perspect. 2013;121(11-12):1357.

47. Genuneit J. Exposure to farming environments in childhood and asthma and wheeze in rural populations: a systematic review with meta-analysis. Pediatr Allergy Immunol. 2012;23(6):509-518.

48. Brunekreef B, Von Mutius E, Wong G, Odhiambo J, García-Marcos L, Foliakf S. Exposure to cats and dogs, and symptoms of asthma, rhinoconjunctivitis, and eczema. Epidemiology. 2012:742-750.

49. Gilliland FD, Islam T, Berhane $\mathrm{K}$, et al. Regular smoking and asthma incidence in adolescents. Am J Respir Crit Care Med. 2006;174(10):1094-1100.

50. Gilliland FD, Li Y-F, Dubeau L, et al. Effects of glutathione S-transferase M1, maternal smoking during pregnancy, and environmental tobacco smoke on asthma and wheezing in children. Am J Respir Crit Care Med. 2002;166(4):457-463. 